\title{
Clinical condition at mid-to-late follow-up after transatrial-transpulmonary repair of tetralogy of Fallot
}

\author{
Jochem van den Berg, MD, a,b Wim C. Hop, PhD, ${ }^{c}$ Jan L. M. Strengers, MD, PhD, Johan C. de Jongste, MD, PhD, \\ Lennie van Osch-Gevers, MD, PhD, ${ }^{a}$ Folkert J. Meijboom, MD, PhD, ${ }^{f}$ Peter M. T. Pattynama, MD, PhD, ${ }^{b}$ \\ Ad J. J. C. Bogers, MD, PhD, ${ }^{g}$ and Willem A. Helbing, MD, PhD ${ }^{a, b}$
}

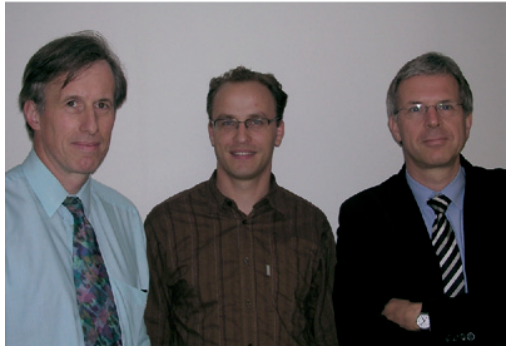

Drs Bogers, van den Berg, and Helbing (left to right)

Earn CME credits at http:// cme.ctsnetjournals.org
From the Departments of Paediatric Cardiology, ${ }^{\mathrm{a}}$ Radiology, ${ }^{\mathrm{b}}$ Epidemiology and Biostatistics ${ }^{\mathrm{c}}$ Paediatric Pulmonology ${ }^{\mathrm{e}}$ Cardi$\operatorname{ology}^{\mathrm{f}}$ and Cardiothoracic Surgery, ${ }^{\mathrm{g}}$ Erasmus MC, Rotterdam, The Netherlands; the Department of Paediatric Cardiology, ${ }^{\mathrm{d}}$ University MC, Wilhelmina Children's Hospital, Utrecht, The Netherlands.

Received for publication July 3, 2006; revisions received Sept 28, 2006; accepted for publication Oct 9, 2006

Address for reprints: W.A. Helbing, MD, $\mathrm{PhD}$, Department of Paediatric Cardiology, Erasmus MC-Sophia Children's Hospital, Sp-2429, Dr Molewaterplein 60, 3015 GJ Rotterdam, The Netherlands (E-mail: w.a.helbing@erasmusmc.nl).

J Thorac Cardiovasc Surg 2007;133:470-7

$0022-5223 / \$ 32.00$

Copyright (๑) 2007 by The American Association for Thoracic Surgery

doi:10.1016/j.jtcvs.2006.10.022
Objectives: To assess the clinical condition at mid-to-late follow-up in tetralogy of Fallot corrected by a transatrial-transpulmonary approach at a young age and to identify risk factors associated with right ventricular dilation/dysfunction and with decreased exercise tolerance.

Methods: Patients with tetralogy of Fallot underwent cardiac magnetic resonance imaging, maximal bicycle ergometry, electrocardiography, Holter monitoring, and spirometry. Multivariate linear regression analyses were used to determine independent predictors for selected clinical parameters.

Results: Fifty-nine patients (mean $\pm \mathrm{SD}$ ), age at repair $0.9 \pm 0.5$ years, interval since repair $14 \pm 5$ years, were included. The median pulmonary regurgitant fraction was 32\% (0\%-57\%). Compared with published data on healthy controls, Fallot patients had significantly larger right ventricular end-diastolic and endsystolic volumes and smaller right ventricular and left ventricular ejection fractions. Maximum oxygen consumption was $97 \% \pm 17 \%$ and maximum workload $89 \% \pm$ $13 \%$ of predicted. Median QRS duration was $110 \mathrm{~ms}$ (82-161 ms). No important ventricular arrhythmias were found. Compared with patients without a transannular patch, patients with a patch had more pulmonary regurgitation, a larger right ventricle, worse right ventricular and left ventricular ejection fractions, but comparable exercise capacity. Multivariate regression analysis identified the following independent determinants for larger right ventricular volumes: longer interval since repair, longer QRS duration, and higher pulmonary regurgitation percentage. The following were independent determinants for smaller right ventricular ejection fraction: abnormal right ventricular outflow tract wall motion, longer interval since repair, and longer QRS duration. For smaller maximum oxygen consumption, the independent determinants were smaller right ventricular ejection fraction and longer QRS duration.

Conclusions: At mid-to-late follow-up, clinical condition in tetralogy of Fallot corrected according to contemporary surgical approaches appears well preserved. However, even these patients show right ventricular dilation and dysfunction associated with impaired functional capacity. Abnormalities relate to right ventricular outflow tract motion abnormalities, longer interval since repair, longer QRS duration, and more severe pulmonary regurgitation.

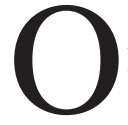
ver the past decades, perioperative mortality of correction for tetralogy of Fallot (TOF) decreased for all ages, including infants. ${ }^{1,2}$ Repair at a young age shortens the period the patient is subjected to systemic hypoxemia and to right ventricular (RV) pressure overload. These considerations have led to a trend of primary correction performed at a young age, aimed at optimal relief of RV outflow tract (RVOT) obstruction and closure of the VSD. ${ }^{1,2}$ In addition, the 


$$
\begin{array}{ll}
\text { Abbreviations and Acronyms } \\
\begin{aligned}
\mathrm{CMR} & =\text { cardiac magnetic resonance imaging } \\
\mathrm{FVC} & =\text { forced vital capacity } \\
\mathrm{LV} & =\text { left ventricular } \\
\mathrm{PR} & =\text { pulmonary regurgitation } \\
\mathrm{RQ} & =\text { respiratory quotient } \\
\mathrm{RV} & =\text { right ventricular } \\
\mathrm{TAP} & =\text { transannular patch } \\
\mathrm{TE} & =\text { echo time } \\
\mathrm{TOF} & =\text { tetralogy of Fallot } \\
\mathrm{VO}_{2 \max } & =\text { maximum oxygen consumption } \\
\mathrm{VSD} & =\text { ventricular septal defect }
\end{aligned}
\end{array}
$$

concept of transatrial-transpulmonary repair for TOF gained popularity. ${ }^{3}$ This concept aims at reducing the side effects associated with a ventriculotomy, such as RV myocardial and coronary artery damage. Outcome of TOF repair has been described extensively. Pulmonary regurgitation (PR) is a crucial factor in long-term outcome. ${ }^{4}$ There is a lack of studies reporting on long-term follow-up, acquired with appropriate tools, in patients with TOF repaired according to recent surgical strategies. Furthermore, most studies have included a mixture of patients with optimal and suboptimal surgical results, such as residual VSD or important pulmonary stenosis. This precludes assessment of optimal long-term effects of repair of TOF and of factors associated with decline in clinical state after optimal repair, that is, clinical condition in patients with (inevitable) PR, but without additional problems. Therefore, the present study aimed (1) to assess clinical condition at midterm to long-term follow-up, including assessment of biventricular volumes and function by cardiac magnetic resonance imaging (CMR) and (2) to identify factors associated with RV dilation, RV dysfunction, and decreased exercise tolerance in patients with TOF operated on at a young age by the transatrial-transpulmonary approach and without residual VSD or important pulmonary stenosis.

\section{Patients and Methods}

A cross-sectional study of patients after surgical repair of TOF was performed. The local medical ethics committee approved our study protocol. Informed consent was obtained from patients or parents if patients were not of the legal age to provide consent. Patients were included for data collection between September 2002 and November 2004. The following inclusion criteria were used: (1) complete repair of TOF without associated cardiac lesions, including double-outlet right ventricle (except patent ductus arteriosus), (2) age at repair 24 months years or younger, (3) transatrialtranspulmonary approach to repair, and (4) duration of postrepair follow-up of 5 years or more. Patients with one or more of the following criteria were excluded: residual VSD, residual pulmonary stenosis (echo Doppler mean gradient $>30 \mathrm{~mm} \mathrm{Hg}$ ), repair with a homograft, mental retardation, and known extracardiac pathologic condition. Criteria were reviewed by use of the patient's medical records. Preoperative hemodynamic data were obtained from diagnostic heart catheterization reports.

\section{Magnetic Resonance Imaging Protocol}

A 1.5-Tesla Signa CVi scanner was used with software releases V8 and V9.1 (General Electric, Milwaukee, Wis). A cine volumetric dataset was acquired in short-axis direction using a 2-dimensional fast imaging employing steady-state acquisition sequence (steadystate free precession). Imaging parameters were as follows: flip angle $=45^{\circ}$, echo time (TE) set at minutes full, repetition time $(\mathrm{TR})=3.4-3.6 \mathrm{~ms}, 8$-to 9-mm slice thickness, 0 - to $1-\mathrm{mm}$ interslice gap, 12 views/segment, readout bandwidth $=111 \mathrm{KHz}$, a square field of vision (30-34 cm), and a scanning matrix of 160 - 128. Twenty-four phases per cardiac cycle were reconstructed retrospectively.

Pulmonary valve flow measurements were performed perpendicular to flow using a standard 2-dimensional retrospectively gated flow-sensitized sequence. Thirty cardiac phases were reconstructed retrospectively. Imaging parameters were as follows: 2-dimensional fast spoiled gradient echo, $\mathrm{TR}=6$ to $7 \mathrm{~ms}$, TE $=$ $3 \mathrm{~ms}$, flip angle $=20^{\circ}$, readout bandwidth $=90 \mathrm{KHz}, 6-\mathrm{mm}$ slice thickness, 6 views/segment, a rectangular field of vision (75\% in phase encoding direction), and a scanning matrix of $256 \cdot 128$.

\section{Magnetic Resonance Image Analysis}

CMR studies were analyzed on an Advanced Windows workstation (General Electric, Milwaukee, Wis). Flow images were quantitatively analyzed with the Flow analysis software package V2.0 (Medis Medical Imaging Systems, Leiden, The Netherlands). Residual pulmonary stenosis was calculated with the simplified Bernoulli equation $\left(\Delta \mathrm{P}=4 \cdot \mathrm{Vmax}^{2}\right)$. Volumetric data were quantitatively analyzed with the Mass analysis software package V3.1 (Medis Medical Imaging Systems, Leiden, The Netherlands), with parameters assessed according to analysis techniques widely reported in the literature. ${ }^{5}$ Volumetric CMR parameters were indexed for body surface area unless specified otherwise. Values outside the mean $\pm 2 \mathrm{SD}$ range in healthy controls were defined to be abnormal. On the cines an experienced observer assessed wall motion in the RVOT. Abnormal wall motion was defined as absent or outward movement of part of the RVOT wall during systole. To calculate the PR fraction, amount of PR was normalized for the systolic stroke volume across the pulmonary valve (PR percentage $\mathrm{e}=$ Backward flow/Systolic forward flow $\cdot 100 \%$ ). Critical upper limits for RV end-diastolic volume, $200 \mathrm{~mL} / \mathrm{m}^{2}$ in children and $170 \mathrm{~mL} / \mathrm{m}^{2}$ in adults, associated with absent return of RV volume to normal size after pulmonary valve replacement have been reported and were applied on our population. ${ }^{6,7}$

\section{Bicycle Ergometry}

Patients performed a symptom-limited bicycle exercise test on a Jaëger Oxycom Champion System (Viasys Healthcare, Hoechberg, Germany), allowing breath-by-breath-ergometry. Workload was increased with 10 to 20 Watts per minute. Patients were encouraged to perform to exhaustion. Tests were regarded as maximal with a respiratory quotient (RQ) of 1.05 or greater in children and 1.10 or greater in adults at peak exercise. Exercise capacity was compared with that of normal individuals, corrected 
for age, sex, and weight. ${ }^{8}$ Values greater than $85 \%$ of predicted were considered normal.

\section{Spirometry}

Preceding the exercise test, patients performed a standard maximal forced vital capacity (FVC) maneuver using a dry rolling seal spirometer (Jaëger, Würzburg, Germany). From the obtained loops the following parameters were derived: FVC, forced expiratory volume in the first second $\left(\mathrm{FEV}_{1}\right)$, ratio $\mathrm{FEV}_{1} / \mathrm{FVC}$, and maximum expiratory flow at $25 \%$ of FVC. Results were compared with those from normal individuals corrected for age, gender, and body composition and expressed as percentages of predicted values.

\section{Electrocardiogram}

A standardized 12-lead electrocardiogram was obtained to assess QRS (ms), QT corrected for heart rate (QTc; ms), and JT corrected for heart rate (JTc; ms) duration. A 24-hour Holter monitoring was performed on a day with usual activities.

\section{Statistical Analysis}

CMR results of patients were compared with a reference population from the literature using the 2-sample $t$ test. ${ }^{9}$ Data were $\log _{10}$-transformed when appropriate to obtain approximately normal distribution. Results are expressed as mean \pm SD for normally distributed data, otherwise as the median and range. Bivariate correlation coefficients were calculated by the Spearman method. Multivariate linear regression analyses (backward stepwise regression method) were used to determine major independent predictors for outcome variables. Only variables significant in univariate analysis were included in these multivariate analyses. Percentages were compared by the $\chi^{2}$ test. Analysis was performed with the SPSS-PC statistical software package version 11.5 (SPSS, Chicago, Ill).

\section{Results}

\section{Patient Characteristics}

Records of 169 eligible patients alive in 2002 and operated on between 1980 and 1997 before the age of 2 years by a transatrial-transpulmonary approach at the Erasmus MC Rotterdam or the University MC Utrecht were checked. Reasons for exclusion were as follows: residual VSD ( $\mathrm{n}=$ 3), residual RVOT stenosis $(>30 \mathrm{~mm} \mathrm{Hg})(\mathrm{n}=11)$, repair with a homograft $(n=15)$, mental retardation $(n=16)$, extracardiac disease $(n=7)$, and lost to follow-up $(n=32)$. Eighty-five patients fulfilled all inclusion criteria and received an invitation for this study. Sixty-three (74\%) patients agreed to participate. Four of our youngest participants (aged 5.9-6.5 years) did not complete the entire protocol and were excluded from all results. The characteristics of the remaining 59 patients are shown in Table 1. Patients who refused to participate and those lost to follow-up did not differ from participants in mean age at repair, interval since repair, incidence of staged repairs, or gender distribution. Patients did not use cardiac medication, $51(86 \%)$ were in New York Heart Association class I $(86 \%)$, and $8(14 \%)$ in class II.
TABLE 1. Patient characteristics

\begin{tabular}{lc}
\hline & $\begin{array}{c}\text { Patient total, } \\
\mathbf{n}=\mathbf{5 9}(\mathbf{1 0 0 \%})\end{array}$ \\
\hline Gender (M/F) & $41 / 18$ \\
Age at repair (y) & $0.8(0.2-2.0)$ \\
Age at study (y) & $15(6-23)$ \\
Interval since repair (y) & $14(6-23)$ \\
BSA (m²) & $1.5 \pm 0.4$ \\
Previous Blalock-Taussing shunt & $3(5 \%)$ \\
Preoperative measures & \\
RV/aortic peak pressure ratio & $1.0 \pm 0.1$ \\
RV peak pressure (mm Hg) & $88 \pm 9$ \\
Oxygen saturation (\%) & $87(62-100)$ \\
Residual pulmonary stenosis (mm Hg) & $9(3-29)$ \\
\hline
\end{tabular}

Data given are mean $\pm S D$ and median (range). $B S A$, Body surface area; $R V$, right ventricle.

In $42(71 \%)$ patients a transannular patch (TAP) repair was performed. In the remaining 17 (29\%) patients desobstruction of the RVOT was achieved by a combination of the following techniques: infundibulectomy, valvulotomy, commissurotomy, and partial valvectomy. Before repair, patients with a TAP had a lower arterial oxygen saturation $(86 \% \pm 9 \%$ vs $92 \% \pm 9 \% ; P<.05)$ and a higher RV/aortic peak pressure ratio $(1.0 \pm 0.1$ vs $0.9 \pm 0.1 ; P<.05)$ than did patients without a TAP. TAP repairs were performed at a younger age (median age at repair 0.6 years [0.2-2.0 years] versus 1.1 [range $0.3-2.0$ ]; $P<.05$ ). Interval since repair was comparable between patients with a TAP and those without $(15 \pm 5$ years versus $13 \pm 4$ years; $P=.14$ ).

\section{CMR}

The median value for PR percentage was 35\% (range 0\%57\%). Patient CMR data were compared with data from the literature assessed in healthy controls (Table 2). ${ }^{9}$ Differences in CMR findings between patients with and without a TAP are shown in Table 3. Abnormal wall motion in the RVOT region was diagnosed in $41(69 \%)$ patients. Cumulative incidence of abnormal wall motion was larger in patients with a TAP than in those without (37/42 patients vs $4 / 17 ; \chi^{2}$ test $\left.<.001\right)$. Similar differences as for patients with or without a TAP were found with regard to PR, biventricular size, and ejection fraction when comparisons were made for patients with abnormal RVOT wall motion versus those with normal wall motion (data not shown).

The RV end-diastolic volume was greater than 170 $\mathrm{mL} / \mathrm{m}^{2}$ in $14(24 \%)$ patients and more than 200 in $4(7 \%)$. Compared with patients with an RV end-diastolic volume of $170 \mathrm{~mL} / \mathrm{m}^{2}$ or less, patients with an RV end-diastolic volume greater than 170 had a smaller RV ejection fraction $(50 \% \pm 6 \%$ vs $44 \% \pm 5 \% ; P<.05)$, comparable left ventricular (LV) ejection fraction $(57 \% \pm 6 \%$ vs $55 \% \pm$ $6 \%$; not significant), and worse exercise capacity (percent- 
TABLE 2. Biventricular CMR results in patients and controls

\begin{tabular}{|c|c|c|c|c|c|}
\hline & \multicolumn{2}{|c|}{ TOF patients } & \multicolumn{2}{|c|}{ Controls } & \multirow[t]{2}{*}{ Abnormalt } \\
\hline No. of patients & \multicolumn{2}{|c|}{59} & \multicolumn{2}{|c|}{16} & \\
\hline \multirow[t]{2}{*}{ Age (y) } & \multicolumn{2}{|c|}{$15 \pm 5$} & \multicolumn{2}{|c|}{$18 \pm 2$} & \\
\hline & Mean \pm SD & Range & Mean \pm SD & Limit & $\mathbf{N}(\%)$ \\
\hline RVEDV $\left(\mathrm{mL} / \mathrm{m}^{2}\right)$ & $139 \pm 37^{*}$ & $85-237$ & $79 \pm 9$ & 97 (UL) & $50(85 \%)$ \\
\hline RVESV $\left(\mathrm{mL} / \mathrm{m}^{2}\right)$ & $72 \pm 26^{*}$ & $35-145$ & $32 \pm 7$ & 56 (UL) & $50(85 \%)$ \\
\hline RVSV $\left(\mathrm{mL} / \mathrm{m}^{2}\right)$ & $66 \pm 14^{*}$ & $36-100$ & $49 \pm 6$ & 61 (UL) & $38(64 \%)$ \\
\hline RVEF (\%) & $49 \pm 6^{*}$ & $32-60$ & $61 \pm 6$ & 49 (LL) & $29(49 \%)$ \\
\hline LVEDV $\left(\mathrm{mL} / \mathrm{m}^{2}\right)$ & $81 \pm 12$ & 61-109 & $79 \pm 9$ & 97 (UL) & $7(12 \%)$ \\
\hline LVESV $\left(\mathrm{mL} / \mathrm{m}^{2}\right)$ & $36 \pm 8^{*}$ & $16-53$ & $29 \pm 7$ & 43 (UL) & $10(17 \%)$ \\
\hline $\operatorname{LVSV}\left(\mathrm{mL} / \mathrm{m}^{2}\right)$ & $46 \pm 7$ & $31-67$ & $49 \pm 6$ & 37 (LL) & $4(7 \%)$ \\
\hline LVEF (\%) & $56 \pm 6^{*}$ & $42-74$ & $63 \pm 6$ & 51 (LL) & $7(12 \%)$ \\
\hline
\end{tabular}

Limits of normal: $U L$ (upper limit) $=$ mean +2 SD; $L L$ (lower limit) = mean -2 SD. CMR, Cardiac magnetic resonance imaging; TOF, tetralogy of Fallot; $R V E D V$, right ventricular end-diastolic volume; RVESV, right ventricular end-systolic volume; RVSV, right ventricular stroke volume; RVEF, right ventricular ejection fraction; $L V E D V$, left ventricular end-diastolic volume; $L V E S V$, left ventricular end-systolic volume; $L V S V$, left ventricular stroke volume; $L V E F$, left ventricular ejection fraction; $S D$, standard deviation. *Significant difference $(P<.05)$ compared with controls. $\dagger$ Number of patients with abnormal CMR results (above UL or below LL of relevance).

age of predicted maximum (peak) oxygen consumption $\left[\mathrm{Vo}_{2 \max }\right] 99 \% \pm 18 \%$ vs $\left.90 \% \pm 11 \% ; P<.05\right)$. All patients with RV end-diastolic volume greater than 170 $\mathrm{mL} / \mathrm{m}^{2}$ had 12 years or more of follow-up (median 18 years, range 12-23) and a PR percentage greater than $30 \%$ (median $46 \%$, range $31 \%-54 \%$ ).

TABLE 3. Comparison of patients according to presence of a TAP in the RVOT*

\begin{tabular}{|c|c|c|}
\hline & $\begin{array}{c}\text { No patch, } \\
\mathrm{n}=17(29 \%)\end{array}$ & $\begin{array}{c}\text { TAP repair, } \\
n=42(71 \%)\end{array}$ \\
\hline PR percentage & $14 \pm 12$ & $40 \pm 11 \dagger$ \\
\hline Residual pulmonary stenosis & $13 \pm 7$ & $9 \pm 6 \dagger$ \\
\hline RVEDV $\left(\mathrm{mL} / \mathrm{m}^{2}\right)$ & $106 \pm 19$ & $152 \pm 35 \dagger$ \\
\hline RVESV $\left(\mathrm{mL} / \mathrm{m}^{2}\right)$ & $51 \pm 12$ & $81 \pm 25 \dagger$ \\
\hline $\operatorname{RVSV}\left(\mathrm{mL} / \mathrm{m}^{2}\right)$ & $55 \pm 10$ & $71 \pm 13 \dagger$ \\
\hline RVEF (\%) & $52 \pm 6$ & $47 \pm 6 \dagger$ \\
\hline RVFWM $\left(\mathrm{g} / \mathrm{m}^{2}\right)$ & $20 \pm 4$ & $26 \pm 6 \dagger$ \\
\hline LVEDV $\left(\mathrm{mL} / \mathrm{m}^{2}\right)$ & $82 \pm 12$ & $81 \pm 12$ \\
\hline LVESV $\left(\mathrm{mL} / \mathrm{m}^{2}\right)$ & $34 \pm 8$ & $37 \pm 8$ \\
\hline LVSV (mL/m²) & $48 \pm 8$ & $45 \pm 7$ \\
\hline $\operatorname{LVEF}(\%)$ & $59 \pm 6$ & $55 \pm 5 \dagger$ \\
\hline $\operatorname{LVM}\left(\mathrm{g} / \mathrm{m}^{2}\right)$ & $52 \pm 9$ & $53 \pm 10$ \\
\hline
\end{tabular}

Data given are mean $\pm \mathrm{SD}$. TAP, Transannular patch; RVOT, right ventricular outflow tract; $P R$, pulmonary regurgitation; RVEDV, right ventricular end-diastolic volume; RVESV, right ventricular end-systolic volume; RVSV, right ventricular stroke volume; $R V E F$, right ventricular ejection fraction; RVFWM, right ventricular free wall mass; $L V E D V$, left ventricular enddiastolic volume; $L V E S V$, left ventricular end-systolic volume; LVSV, left ventricular stroke volume; $L V E F$, left ventricular ejection fraction; $L V M$, left ventricular mass. All CMR parameters were indexed for body surface area. * Similar differences with regard to PR, biventricular size, wall mass and EF were found when comparisons were made for patients with normal and abnormal RVOT wall-motion (data not shown). †Significant difference compared with patients without a patch in the RVOT ( $t$ test, $P<.05$ )

\section{Electrocardiogram and Holter Monitoring}

All patients were in sinus rhythm. Right bundle branch block was diagnosed in $80 \%$ of patients. Median QRS duration was $110 \mathrm{~ms}$ (range 82-161 ms), mean QTc duration was $408 \pm 32 \mathrm{~ms}$, and mean JTc duration was $270 \pm$ $23 \mathrm{~ms}$. No differences were found for QRS duration $(P=$ $.47)$, QTc duration $(P=.39)$, and JTc duration $(P=0.26)$ between patients with or without a TAP.

During 24-hour Holter monitoring, 5 patients showed one or more cardiac pauses of more than 1.9 second. The longest observed pause lasted 2.3 seconds. Two patients, both with a TAP, showed a nonsustained ventricular tachycardia run of respectively 3 and 4 complexes at heart rates of 174 and 108 beats/min with a QRS duration in sinus rhythm of 105 and $130 \mathrm{~ms}$, respectively.

\section{Spirometry}

Mean $\mathrm{FEV}_{1}$ was $99 \% \pm 12 \%$ of predicted. Mean FVC was $94 \% \pm 12 \%$ of predicted. The median $\mathrm{FEV}_{1} / \mathrm{FVC}$ ratio was $89 \%$ (range $75 \%-100 \%$ ). Mean maximum expiratory flow at $25 \%$ of FVC was $89 \% \pm 31 \%$ of predicted. Mean FVC of predicted tended to be higher in patients without a TAP $(97 \% \pm 14 \%$ vs $90 \% \pm 12 \% ; P=.05)$. The other parameters were not different between patients with and without a TAP.

One patient showed severe obstructive abnormalities, and exercise results of this patient were excluded from analysis. The parameters derived from the maximal flowvolume loops showed no significant correlations with percentage of predicted $\mathrm{Vo}_{2 \max }$.

\section{Bicycle Ergometry}

The patient with obstructive airway disease was excluded, 1 patient declined the test, and 1 patient could not complete 
TABLE 4. Predictors of peak oxygen consumption $\left(\mathrm{V}_{\mathbf{0}_{2}}\right)$

\begin{tabular}{|c|c|c|c|c|}
\hline \multirow[b]{2}{*}{ Predictor } & \multicolumn{2}{|c|}{ Univariate analysis } & \multicolumn{2}{|c|}{ Multivariate analysis } \\
\hline & Regression coefficient \pm SE & $P$ value & Regression coefficient \pm SE & $P$ value \\
\hline \multicolumn{5}{|l|}{ Dependent: $\mathrm{V}_{0_{2}}\left(\mathrm{~mL} \cdot \mathrm{kg}^{-1} \cdot \min ^{-1}\right)$} \\
\hline $\operatorname{LVSV}\left(\mathrm{mL} / \mathrm{m}^{2}\right)$ & $0.5 \pm 0.2$ & .002 & $0.4 \pm 0.1$ & .001 \\
\hline Gender (M/F) & $-7.0 \pm 2.2$ & .002 & $5.9 \pm 1.8$ & .002 \\
\hline Interval since repair (y) & $-0.6 \pm 0.2$ & .004 & $-0.5 \pm 0.2$ & .004 \\
\hline QRS duration (ms) & $-0.15 \pm 0.06$ & .008 & $-0.10 \pm 0.05$ & .04 \\
\hline Constant & & & $34.9 \pm 7.5$ & - \\
\hline RVEF (\%) & $0.53 \pm 0.16$ & .002 & & NS \\
\hline PR percentage & $-0.17 \pm 0.06$ & .009 & & NS \\
\hline TAP (yes/no) & $4.8 \pm 2.2$ & .04 & & NS \\
\hline RVOT motion (abnormal/normal) & $-5.3 \pm 2.2$ & .02 & & NS \\
\hline RV peak pressure (mm Hg) & $-0.18 \pm 0.08$ & .03 & & NS \\
\hline \multicolumn{5}{|c|}{ Dependent: $\mathrm{VO}_{2}$ percentage of predicted } \\
\hline RVEF $(\%)$ & $1.6 \pm 0.3$ & $<.001$ & $1.3 \pm 0.3$ & $<.001$ \\
\hline QRS duration (ms) & $-0.4 \pm 0.1$ & .001 & $-0.2 \pm 0.1$ & .05 \\
\hline Constant & & & $59.4 \pm 24.1$ & - \\
\hline RVESV $\left(\mathrm{mL} / \mathrm{m}^{2}\right)$ & $-0.23 \pm 0.09$ & .009 & & NS \\
\hline $\operatorname{LVSV}\left(\mathrm{mL} / \mathrm{m}^{2}\right)$ & $0.8 \pm 0.3$ & .02 & & NS \\
\hline $\operatorname{LVEF}(\%)$ & $1.2 \pm 0.4$ & .002 & & NS \\
\hline Interval since repair (y) & $-1.5 \pm 0.4$ & .001 & & NS \\
\hline RV peak pressure $(\mathrm{mm} \mathrm{Hg})$ & $-0.39 \pm 0.16$ & .02 & & NS \\
\hline
\end{tabular}

Data given are regression coefficients \pm standard errors. $R^{2}$ for the multiple regression model of $\mathrm{Vo}_{2}\left(\mathrm{~mL} \cdot \mathrm{kg}^{-1} \cdot \mathrm{min}^{-1}\right)$ and $\mathrm{V}_{2}($ percentage of predicted) were respectively 0.49 and 0.36 .

$L V S V$, Left ventricular stroke volume; $R V E F$, right ventricular ejection fraction; $P R$, pulmonary regurgitation; $T A P$, transannular patch; $R V O T$, right ventricular outflow tract; $R V$, right ventricular; $R V E S V$, right ventricular end-systolic volume; $L V S V$, left ventricular stroke volume; $L V E F$, left ventricular ejection fraction; $N S$, not significant.

the test as a result of technical problems. Exercise data reflect results of the remaining 56 patients. Mean RQ at peak exercise was $1.2 \pm 0.1$. All patients reached our RQ criteria at peak exercise. Age at study correlated positively with RQ at peak exercise $(r=0.44 ; P<.001)$ and RQ during initial recovery $(r=0.69 ; P<.001) . \mathrm{Vo}_{2 \max }$ was 40 $\pm 8 \mathrm{~mL} \cdot \mathrm{kg}^{-1} \cdot \mathrm{min}^{-1}$, or $97 \% \pm 17 \%$ of predicted $\mathrm{Vo}_{2 \max }$ $(P=.20)$, with a value less than $85 \%$ found in $14(25 \%)$ patients. Mean peak workload was $149 \pm 62$ Watts, or $89 \%$ $\pm 13 \%$ of predicted $(P<.05)$, with value less than $85 \%$ found in $18(32 \%)$ patients.

Percentage of predicted workload and percentage of predicted $\mathrm{VO}_{2 \max }$ were not different between patients with a TAP and those without a TAP (respectively, $88 \% \pm 11 \%$ vs $92 \% \pm 17 \% ; P=.37$; and $96 \% \pm 15 \%$ vs $99 \% \pm 22 \% ; P$ $=.59$ ). Percentage of predicted workload and percentage of predicted $\mathrm{VO}_{2 \max }$ were smaller in patients with abnormal RVOT wall motion than in patients with normal motion (respectively, $86 \% \pm 12 \%$ vs $95 \% \pm 13 \% ; P<.05$; and $94 \% \pm 16 \%$ vs $103 \% \pm 19 \% ; P=.07)$.

\section{Determinants of Exercise Capacity}

Factors significantly related to $\mathrm{VO}_{2 \max }$ and percentage of predicted $\mathrm{VO}_{2 \max }$ by univariate analysis were determined. Predictor variables originated from the following 3 sets of parameters: (1) parameters determined at prerepair diagnostic heart catheterization (RV peak pressure, arterial oxygen saturation, RV/aortic pressure ratio), (2) perioperative parameters (age at repair, TAP [0 = present, $1=$ absent $]$ ), and (3) postoperative parameters (PR percentage, interval since repair, RVOT wall motion [0 = abnormal, $1=$ normal $]$, QRS duration, QTc, JTc, and all biventricular CMR determined measures).

Variables with significant relations (at the .05 level) identified by univariate analysis were used in multiple regression analysis to identify independent determinants. Results for both the univariate and multivariate linear regression analyses are shown in Table 4.

\section{Determinants of RV CMR Measures and PR Percentage}

RV CMR parameters and PR percentage were analyzed by the same procedures described in the previous paragraph. During analyses on RV end-diastolic volume, end-systolic volume, and ejection fraction, the corresponding LV parameter was introduced in the model. Mathematically related RV CMR measures were not used in one model. Results for both the univariate and multivariate linear regression analyses are shown in Table 5. 
TABLE 5. Predictors of RV CMR measures

\begin{tabular}{|c|c|c|c|c|}
\hline \multirow[b]{2}{*}{ Predictor } & \multicolumn{2}{|c|}{ Univariate analysis } & \multicolumn{2}{|c|}{ Multivariate analysis } \\
\hline & Regression coefficient \pm SE & $P$ value & Regression coefficient \pm SE & $P$ value \\
\hline \multicolumn{5}{|l|}{ Dependent: RVEDV $\left(\mathrm{mL} / \mathrm{m}^{2}\right)$} \\
\hline Interval since repair (y) & $3.7 \pm 0.9$ & $<.001$ & $1.4 \pm 0.6$ & $<.05$ \\
\hline PR percentage (\%) & $1.5 \pm 0.2$ & $<.001$ & $1.3 \pm 0.2$ & $<.001$ \\
\hline LVEDV $\left(\mathrm{mL} / \mathrm{m}^{2}\right)$ & $1.3 \pm 0.4$ & .001 & $1.5 \pm 0.2$ & $<.001$ \\
\hline Constant & & & $-54.8 \pm 18.4$ & - \\
\hline TAP (yes/no) & $42 \pm 9$ & $<.001$ & & NS \\
\hline RVOT motion (abnormal/normal) & $7 \pm 9$ & $<.001$ & & NS \\
\hline RV peak pressure (mm Hg) & $1.0 \pm 0.3$ & .005 & & NS \\
\hline \multicolumn{5}{|l|}{ Dependent: $\log _{10}$ RVESV $\left(\mathrm{mL} / \mathrm{m}^{2}\right)$} \\
\hline Interval (y) & $0.016 \pm 0.003$ & $<.001$ & $0.007 \pm 0.003$ & $<.01$ \\
\hline PR percentage & $0.006 \pm 0.001$ & $<.001$ & $0.005 \pm 0.001$ & $<.001$ \\
\hline LVESV $\left(\mathrm{mL} / \mathrm{m}^{2}\right)$ & $0.009 \pm 0.002$ & $<.001$ & $0.007 \pm 0.002$ & $<.001$ \\
\hline QRS duration (ms) & $0.003 \pm 0.001$ & .02 & $0.001 \pm 0.001$ & $<.05$ \\
\hline Constant & & & $1.15 \pm 0.09$ & - \\
\hline RV peak pressure $(\mathrm{mm} \mathrm{Hg})$ & $0.004 \pm 0.001$ & .003 & & NS \\
\hline TAP (yes/no) & $0.17 \pm 0.04$ & $<.001$ & & NS \\
\hline \multicolumn{5}{|l|}{ Dependent: RVEF (\%) } \\
\hline Interval (y) & $-0.59 \pm 0.14$ & $<.001$ & $-0.3 \pm 0.1$ & $<.05$ \\
\hline QRS duration (ms) & $-0.12 \pm 0.04$ & .007 & $-0.07 \pm 0.03$ & $<.05$ \\
\hline LVEF (\%) & $0.49 \pm 0.13$ & .03 & $0.5 \pm 0.1$ & $<.001$ \\
\hline RVOT motion (abnormal/normal) & $5.9 \pm 1.6$ & $<.001$ & $-3.1 \pm 1.4$ & $<.05$ \\
\hline Constant & & & $39.1 \pm 7.0$ & - \\
\hline RV peak pressure $(\mathrm{mm} \mathrm{Hg})$ & $-0.13 \pm 0.06$ & .03 & & NS \\
\hline PR percentage & $-0.12 \pm 0.05$ & .03 & & NS \\
\hline TAP (yes/no) & $-4.7 \pm 1.7$ & .007 & & NS \\
\hline \multicolumn{5}{|l|}{ Dependent: PR percentage } \\
\hline TAP (yes/no) & $22.5 \pm 3.4$ & $<.001$ & $22.2 \pm 3.3$ & $<.001$ \\
\hline RV peak presssure $(\mathrm{mm} \mathrm{Hg})$ & $0.39 \pm 0.14$ & .008 & $0.3 \pm 0.1$ & .02 \\
\hline Constant & & & $-5.7 \pm 9.0$ & - \\
\hline RVOT motion (abnormal/normal) & $-17.9 \pm 4.0$ & $<.001$ & & NS \\
\hline Arterial oxygen saturation & $-0.57 \pm 0.21$ & .01 & & NS \\
\hline Interval since repair (y) & $0.83 \pm 0.41$ & .05 & & NS \\
\hline RV free wall mass $\left(\mathrm{g} / \mathrm{m}^{2}\right)$ & $1.1 \pm 0.3$ & .001 & & NS \\
\hline
\end{tabular}

Data given are regression coefficients \pm standard errors. $R^{2}$ for the multiple regression models of RVEDV, RVESV, RVEF and PR percentage were respectively $0.76,0.72,0.53$ and 0.53 . $R V$, Right ventricular; $C M R$, cardiac magnetic resonance imaging; $R V E D V$, right ventricular end-diastolic volume; $P R$, pulmonary regurgitation; $L V E D V$, left ventricular end-diastolic volume; $T A P$, transannular patch; $R V E F$, right ventricular ejection fraction; $L V E F$, left ventricular ejection fraction; RVOT, right ventricular outflow tract; $L V E S V$, left ventricular end-systolic volume; $L V E F$, left ventricular ejection fraction.

\section{Discussion}

This study provides quantitative data on clinical status at mid-to-late follow-up in patients with TOF corrected at a relatively young age by a transatrial-transpulmonary approach and without other residual lesions but PR. TOF repair almost inevitably results in some degree of PR. Here the median PR percentage was 35\% (range 0\%-57\%). As expected with considerable volume overload, RV volumes were markedly elevated in our patients, with mean values being approximately twice that in controls and values above the upper limit of normal found in $85 \%$ of our patients (Table 2). Furthermore, RV and LV ejection fractions were decreased compared with controls in, respectively, $49 \%$ and $12 \%$ of our patients. Despite these striking abnormalities, chronic RV volume overload seems to be well tolerated by these patients. All were in New York Heart Association class I (86\%) or II (14\%), all were in sinus rhythm, and none used cardiac medication. Mean percentage of predicted $\mathrm{VO}_{2 \max }$ was not different from controls. Patients had normal lung function, and no important ventricular arrhythmias were encountered.

This study identified independent predictors of several undesirable, but common problems during the follow-up of TOF. The most important predictor of poorer exercise capacity was a lower RV ejection fraction, which in turn was best predicted by abnormal RVOT wall motion. Larger RV dilation and poorer RV ejection fraction were associated with a longer interval since repair. This suggests that, even 
in patients with TOF corrected according to current surgical strategies and with optimal surgical result, gradual but slow deterioration of RV function with volume overload seems inevitable. Patients with already marked RV dilation subjected to chronic PR may have symptoms develop over time, which stresses the need for serial follow-up.

\section{RVOT Function in Repaired TOF}

Previous studies have demonstrated the negative impact of TAP repair on PR and RV size. ${ }^{10}$ In our study, multivariate regression analysis showed that TAP repair was the most important independent predictor of PR percentage, with a $22 \% \pm 3 \%$ point higher PR percentage in patients with a TAP than in those without a TAP (Table 5). A higher PR percentage independently predicted larger RV volumes, but not poorer RV ejection fraction. Poorer RV ejection fraction was independently predicted by abnormal RVOT wall motion. A previous study among adult Fallot patients, operated on at older ages than our patients, also found abnormal motion in the RVOT region to predispose for RV dysfunction. ${ }^{10}$ Both that study and ours showed that abnormal wall motion is not restricted to patients with a TAP. This suggests wall motion abnormalities can be induced by other factors. Remarkably, Davlouros and associates ${ }^{10}$ found no difference in incidence of wall motion abnormalities between patients with and without TAP, whereas this difference was clearly present in our patients. This may be explained by the different primary surgical approach used, with a primary ventriculotomy used in most of the cases reported by Davlouros' group. ${ }^{10}$ However, other factors such as prolonged hypoxemia, present in the cases reported by Davlouros and colleagues, ${ }^{10}$ cannot be ruled out to play a role in RV wall motion abnormalities. The influence of surgery in the RVOT region on long-term outcome has also been studied by comparing patients undergoing transventricular TOF repair with patients with isolated pulmonary valve stenosis treated by pulmonary commissurotomy. ${ }^{11}$ Freedom of adverse events related to RV dilation (defined as cardiac death, reoperation, and New York Heart Association class $\geq$ II) was better in patients after isolated commissurotomy despite similar degrees of moderate and severe PR found in both patient groups. These findings suggest that limited RVOT surgery contributes to better long-term outcome, which is supported by our study. Whether or not the recently described reconstructive technique of the pulmonary valve by Sung and colleagues ${ }^{12}$ further contributes to improved outcome remains a matter of ongoing observation.

\section{QRS Duration}

In TOF a QRS duration greater than $180 \mathrm{~ms}$ in adults and greater than $170 \mathrm{~ms}$ in children is known to predispose to malignant ventricular arrhythmia and sudden death. ${ }^{13,14}$
QRS duration did not exceed $170 \mathrm{~ms}$ in our patients. Residual PR and subsequent RV dilation have been associated with QRS prolongation. ${ }^{14-16}$ Pulmonary valve replacement has been shown to reduce QRS duration proportionally to the degree of RV volume reduction. ${ }^{17,18}$ In our population, QRS duration was an independent predictor of RV volume but also of RV ejection fraction and exercise tolerance (Table 5). These predictive effects were present in the range below the reported critical values that predispose for arrhythmia and sudden death.

Prolongation of QRS duration has been related to electrical inhomogeneity. ${ }^{19}$ In this regard, ventricular dyssynchrony has been observed in TOF. Cardiac resynchronization therapy in heart failure with prolonged QRS duration has been proven beneficial for ventricular contractile function, symptomatic status, and mortality. ${ }^{20,21}$ Thus far, results in congenital heart disease including TOF have been promising. ${ }^{19}$ The relations found for QRS duration with RV ejection fraction and exercise capacity in the present study suggest that functional gain may be achieved by cardiac resynchronization therapy in selected patients with TOF.

\section{Long-term Outcome of TOF}

Pulmonary valve replacement currently is the only widely accepted treatment for residual PR in TOF. Optimal timing of this procedure seems crucial, but criteria so far have not been established. ${ }^{4}$ Newer imaging techniques, such as CMR, are expected to supply the data required to design such criteria. Several groups studied outcome of pulmonary valve replacement using serial CMR data. ${ }^{6,7,22}$ An RV enddiastolic volume of $170 \mathrm{~mL} / \mathrm{m}^{2}$ or less in adults and 200 $\mathrm{mL} / \mathrm{m}^{2}$ or less in children was found to relate to adequate recovery of RV volume. ${ }^{6,7}$ Our patients with an RV enddiastolic volume greater than $170 \mathrm{~mL} / \mathrm{m}^{2}$ had worse exercise capacity. Remarkably, all these patients had an interval since repair of 12 years or more and a PR percentage greater than $30 \%$. Patients with a PR percentage of $30 \%$ or less did not demonstrate an RV end-diastolic volume of more than $170 \mathrm{~mL} / \mathrm{m}^{2}$, irrespective of follow-up duration. Most large CMR-based studies report on patients with TOF operated on according to different surgical strategies than our patients (older age at repair, staged repairs, primary RV ventriculotomy, repair with RV-pulmonary artery conduits). ${ }^{10,23} \mathrm{We}$ demonstrate that previously obtained CMR criteria also identify worse clinical status in patients operated on according to a currently widely accepted surgical approach. However, the long-term prognostic value of these criteria regarding mortality and morbidity still has to be determined in patients from any surgical era. ${ }^{7}$

\section{Study Limitations}

Because of the potential negative effect of a ventriculotomy on long-term clinical state, a transatrial-transpulmonary 
approach was chosen in all patients. The frequent use of a TAP illustrates that total avoidance of a ventriculotomy in TOF is not feasible in clinical practice. Furthermore, it created the opportunity to evaluate the effect of a TAP on clinical condition. Inclusion criteria limit this study to patients with "isolated" PR. As such, our patients represent that part of daily clinical practice with optimally repaired initial pathology (VSD and RVOT obstruction). Because of the design, difficulties in data interpretation introduced with various forms of ventricular overload are avoided.

We used CMR reference values from healthy controls of the same age range, obtained and analyzed in similar ways as in the current study. ${ }^{9}$ During the assessment of functional capacity, we did not account for level of physical training. The RQ at peak exercise indicates all patients performed maximally. As expected, results show higher RQ values in older patients. Therefore, peak results may better reflect maximal exercise capacity in older patients. This may have resulted in a slight underestimation of the magnitude of regression in exercise capacity over time.

The debate on optimal age at repair is still ongoing. As all our patients had corrective surgery after the age of 2 months, we can only speculate on further improvement of clinical state if surgical correction was done in the neonatal period. We did not find important effects of age at repair on the outcome measures shown in Tables 4 and 5.

\section{Conclusions}

The current study demonstrates that at mid-to-late followup, symptomatic status, exercise performance, and rhythm status remain relatively normal in patients with TOF after repair according to a transatrial-transpulmonary approach. Deterioration of RV function and exercise capacity correlate with a longer interval since repair, but these moderate associations cannot be used to predict the pace of decline in the individual patient. Our results suggest that further improvement of clinical condition may be obtained by improving preservation of RVOT function and by reducing the effect of electrical inhomogeneity. The evolution of CMR, electrocardiographic, and exercise data in this series, as well as the need for and the effects of interventions, should be re-evaluated in future studies.

\section{References}

1. Knott-Craig CJ, Elkins RC, Lane MM, Holz J, McCue C, Ward KE. A 26-year experience with surgical management of tetralogy of Fallot: risk analysis for mortality or late reintervention. Ann Thorac Surg. 1998;66:506-11.

2. Alexiou C, Mahmoud H, Al-Khaddour A, Gnanapragasam J, Salmon AP, Keeton BR, et al. Outcome after repair of tetralogy of Fallot in the first year of life. Ann Thorac Surg. 2001;71:494-500.

3. Hudspeth A, Cordell A, Johnston F. Transatrial approach to total correction of tetralogy of Fallot. Circulation. 1963;27:796-800.

4. Bouzas B, Kilner PJ, Gatzoulis MA. Pulmonary regurgitation: not a benign lesion. Eur Heart J. 2005;26:433-9.
5. Helbing WA, de Roos A. Clinical applications of cardiac magnetic resonance imaging after repair of tetralogy of Fallot. Pediatr Cardiol. 2000;21:70-9.

6. Buechel ER, Dave HH, Kellenberger CJ, Dodge-Khatami A, Pretre R, Berger F, et al. Remodelling of the right ventricle after early pulmonary valve replacement in children with repaired tetralogy of Fallot: assessment by cardiovascular magnetic resonance. Eur Heart J. 2005; 26:2721-7.

7. Therrien J, Provost Y, Merchant N, Williams W, Colman J, Webb G. Optimal timing for pulmonary valve replacement in adults after tetralogy of Fallot repair. Am J Cardiol. 2005;95:779-82.

8. Wasserman K, Hansen JE, Sue DY, Casaburi R, Whipp BJ. Principles of exercise testing and interpretation. Normal values. Philadelphia: Lippincott Williams \& Wilkins. 1999. p. 143-64.

9. Roest AA, Helbing WA, Kunz P, van den Aardweg JG, Lamb HJ, Vliegen HW, et al. Exercise MR imaging in the assessment of pulmonary regurgitation and biventricular function in patients after tetralogy of Fallot repair. Radiology. 2002;223:204-11.

10. Davlouros PA, Kilner PJ, Hornung TS, Li W, Francis JM, Moon JC, et al. Right ventricular function in adults with repaired tetralogy of Fallot assessed with cardiovascular magnetic resonance imaging: detrimental role of right ventricular outflow aneurysms or akinesia and adverse rightto-left ventricular interaction. $J$ Am Coll Cardiol. 2002;40:2044-52.

11. d'Udekem d'Acoz Y, Pasquet A, Lebreux L, Ovaert C, Mascart F, Robert A, et al. Does right ventricular outflow tract damage play a role in the genesis of late right ventricular dilatation after tetralogy of Fallot repair? Ann Thorac Surg. 2003;76:555-61; discussion 561.

12. Sung SC, Kim S, Woo JS, Lee YS. Pulmonic valve annular enlargement with valve repair in tetralogy of Fallot. Ann Thorac Surg. 2003;75:303-5.

13. Berul CI, Hill SL, Geggel RL, Hijazi ZM, Marx GR, Rhodes J, et al. Electrocardiographic markers of late sudden death risk in postoperative tetralogy of Fallot children. J Cardiovasc Electrophysiol. 1997;8: 1349-56.

14. Gatzoulis MA, Balaji S, Webber SA, Siu SC, Hokanson JS, Poile C, et al. Risk factors for arrhythmia and sudden cardiac death late after repair of tetralogy of Fallot: a multicentre study. Lancet. 2000;356:975-81.

15. Helbing WA, Roest AA, Niezen RA, Vliegen HW, Hazekamp MG, Ottenkamp J, et al. ECG predictors of ventricular arrhythmias and biventricular size and wall mass in tetralogy of Fallot with pulmonary regurgitation. Heart. 2002;88:515-9.

16. Abd El Rahman MY, Abdul-Khaliq H, Vogel M, Alexi-Meskishvili V, Gutberlet M, Lange PE. Relation between right ventricular enlargement, QRS duration, and right ventricular function in patients with tetralogy of Fallot and pulmonary regurgitation after surgical repair. Heart. 2000;84:416-20.

17. van Huysduynen BH, van Straten A, Swenne CA, Maan AC, van Eck $\mathrm{HJ}$, Schalij MJ, et al. Reduction of QRS duration after pulmonary valve replacement in adult Fallot patients is related to reduction of right ventricular volume. Eur Heart J. 2005;26:928-32.

18. Doughan AR, McConnell ME, Lyle TA, Book WM. Effects of pulmonary valve replacement on QRS duration and right ventricular cavity size late after repair of right ventricular outflow tract obstruction. Am J Cardiol. 2005;95:1511-4

19. Khairy P, Fournier A, Thibault B, Dubuc M, Therien J, Vobecky SJ. Cardiac resynchronization therapy in congenital heart disease. Int J Cardiol. 2006;109:160-8.

20. Abraham WT, Fisher WG, Smith AL, Delurgio DB, Leon AR, Loh E, et al. Cardiac resynchronization in chronic heart failure. $N$ Engl J Med. 2002;346:1845-53.

21. Cleland JG, Daubert JC, Erdmann E, Freemantle N, Gras D, Kappenberger $\mathrm{L}$, et al. The effect of cardiac resynchronization on morbidity and mortality in heart failure. $N$ Engl J Med. 2005;352:1539-49.

22. van Straten A, Vliegen HW, Lamb HJ, Roes SD, van der Wall EE, Hazekamp MG, et al. Time course of diastolic and systolic function improvement after pulmonary valve replacement in adult patients with tetralogy of Fallot. J Am Coll Cardiol. 2005;46:1559-64.

23. Geva T, Sandweiss BM, Gauvreau K, Lock JE, Powell AJ. Factors associated with impaired clinical status in long-term survivors of tetralogy of Fallot repair evaluated by magnetic resonance imaging. J Am Coll Cardiol. 2004;43:1068-74. 